\title{
Anti-Tumor Necrosis Factor Therapy
}

National Cancer Institute

\section{Source}

National Cancer Institute. Anti-Tumor Necrosis Factor Therapy. NCI Thesaurus. Code C15577.

Drug treatment to reduce the activity of tumor necrosis factor, particulary to control inflammation in disease modalities. 